Interactive comment on "Dramatic increase of reactive VOC emission from ships at berth after implementing the fuel switch policy in the Pearl River Delta Emission Control Area" by Zhenfeng

\title{
Wu et al.
}

Zhenfeng Wu et al.

zhang_yl86@gig.ac.cn

Received and published: 5 December 2019

The comment was uploaded in the form of a supplement:

https://www.atmos-chem-phys-discuss.net/acp-2019-897/acp-2019-897-AC1-

supplement.pdf 